\title{
A dramaturgia no teatro site-specific
}

The playwright in the site-specific theater

Sofia RODRIGUES BOITO ${ }^{1}$

RESUMO

O artigo debate a criação de dramaturgia em obras teatrais site-specific sob a perspectiva do gesto. Transplantamos o conceito de gesto lírico do crítico literário Dominique Rabaté para o contexto de uma criação teatral em processo colaborativo nas ruas de São Paulo a fim de investigar as possibilidades de emergência de textualidades na relação corporal entre ator e cidade.

Palavras-chave: Site-specific. Intervenção urbana.

Dramaturgia contemporânea.

\section{ABSTRACT}

The article discusses the dramaturgic creation in site-specific theater from the gesture point-of-view. We transferred the concept of lyrical gesture by literary critic Dominique Rabaté to a context of theatrical creation in a collaborative process in the streets of São Paulo, with the aim to investigate the possibility of a textual creation emerging from the relation between actors and the city.

Keywords: Site-specific. Urban intervention. Contemporary dramaturgy.
1. Doutoranda em Artes Cênicas na Universidade de São Paulo. E-mail:

sofiaboito@gmail.com

Submetido em: 14/05/2016, aceito em: 08/06/2016. 
Poderíamos dizer, em uma primeira e inadvertida mirada, que em nada influencia na atividade do escritor/dramaturgo o estado de seu corpo. E que esse artista, entre todos os outros, talvez seja a quem menos importe questões relativas a corporeidade. Homem (ou mulher) das letras, o dramaturgo diferentemente do dançarino, ator e artista visual - pouco se relacionaria com a materialidade dos órgãos. No presente artigo, no entanto, pretendemos aprofundar um pouco a questão e problematizar o lugar do corpo na ação da escrita. Colocamo-nos aqui um desafio: pensar a escrita através do corpo e de sua relação com o mundo - o ambiente em que está inserido -, e desvinculá-la da ideia de atividade racional e isolada. A discussão que será proposta é parte da pesquisa de doutorado que venho desenvolvendo na Universidade de São Paulo e terá como ponto de apoio um espetáculo do qual fui dramaturga, intitulado Antídoto para impossibilidades e paralisias $^{2}$, apresentando em julho de 2015 nas ruas do bairro da Liberdade em São Paulo.

Utilizemos como ponto de partida para este ensaio uma frase de Raymond Williams:

O drama é um elemento tão central na vida de uma sociedade que uma mudança em seus métodos não pode ser isolada de mudanças de alcance muito maior. Enquanto o sentimento das pessoas for trancado em salas fechadas, o drama estará com eles (WILLIAMS, 2010, p. 228).

Essa frase contém dois pontos de extrema relevância para a discussão que pretendemos travar: o lugar ficcional em que se desenvolve o drama e o lugar real de atuação desse. Raymond Williams não desvincula um do outro. Refere-se ao espaço fechado do drama burguês - sempre restrito ao espaço privado e, portanto, ao conflito individual -, e seu alcance real - que também se restringirá ao conflito individual e privado. Williams tampouco descarta a relação entre o espaço de trabalho dos artistas envolvidos - que revelam os espaços praticados por aquela sociedade - e os espaço que será retratado no drama. Se as pessoas, incluindo os artistas, continuam trancafiando seus conflitos e sentimentos dentro de quatro paredes, é lá que o drama estará. A mudança do drama implica na mudança de métodos. $\mathrm{E}$ a mudança de métodos - intrinsicamente ligada à forma de vida naquela sociedade - implicará em uma mudança de alcance do drama.

O alcance do drama, o espaço privado, o espaço público, o lugar do teatro, o edifício teatral, o espaço ficcional, o espaço em que as artes cênicas atuam... Todos esses temas parecem muito pertinentes para o momento atual das artes cênicas no Brasil, ou pelo menos, até onde podemos observar, na cidade
2. O espetáculo, que foi uma co-criação da Cia Temporária de Investigação Cênica e do CAI - Coletivo Autônomo de Intervenções -, teve concepção e direção de Joana Dória de Almeida. Para acessar o vídeo do teaser: https://www.youtube.com/ watch?v=2Dfc57FHweg 
de São Paulo. Referimo-nos aqui à explosão no número de companhias teatrais paulistanas que têm criado espetáculos em espaços urbanos. Ruas, estações de trens, aeroportos, metrôs, hotéis, shopping centers ou parques têm sido locais de trabalho, pesquisa, criação e atuação para inúmeros grupos que, anteriormente, costumavam trabalhar em locais fechados. Tal tendência revela uma crescente preocupação de colocar em debate a estrutura da cidade, a forma como a praticamos, o isolamento e o anestesiamento dos habitantes das grandes metrópoles. Tirar a atividade cênica das salas fechadas, protegidas e privadas a fim de libertar também o drama e o seu campo de atuação.

Podemos supor, assim, que o extravasamento das paredes do edifício teatral tenta restaurar a experiência da cidade, a relação carne-asfalto da qual tanto temos nos protegido para sobreviver à complexa - e cada vez mais difícil - realidade das grandes cidades. São Paulo, talvez por suas características inerentes à uma metrópole de terceiro mundo - violenta, congestionada e poluída -, atinge em tal grau a expropriação da experiência que transforma seu espaço público em local apenas de passagem. Habitantes da cidade se blindam cada vez mais das influências externas e protegem-se de serem afetados pelas mazelas urbanas, não se deixam afetar pela cidade e, também, acabam impossibilitados de afetá-la e transformá-la. Estamos submetidos a uma hipnose coletiva, mesmo quando ela se traveste de "hiperexcitação", tal qual descreve Peter Pál Pelbert (2007).

Há um apaziguamento forçado das contradições econômico-sociais que vivemos, homogeneizando e pasteurizando nossos desejos e pensamentos. Tal estado de anestesiamento da população tem relação direta com a "diluição das possibilidades de experiência na cidade contemporânea", como afirma Paola Berenstein Jacques (2012). A homogeneização do medo e o consenso de que estamos mais seguros em ambientes privados, são características dessa cidade que nos assusta e enclausura. As ruas foram transformadas em locais de passagens, onde nos sentimos seguros apenas em nossos automóveis - pequenos espaços privados de locomoção -, evitando o contato com o perigo lá fora - mantendo os nossos vidros fechados - acabando com a relação corpo a corpo com a cidade. É no sentido da restauração dessa experiência que surgem diversos trabalhos de performer, dançarinos, atores, e encenadores que pesquisam a urbe. Mas enquanto tais artistas investigam corporalmente a arquitetura da cidades, propõem outros usos para seus lugares mortos, descobrem novas formas de se movimentar pelo espaço urbano ou propõe outras maneiras de se relacionar com os transeuntes, qual é o lugar do texto e do dramaturgo nesse novo horizonte de criação? Isolar a atividade 
do dramaturgo entre quatro paredes não seria, por fim, isolar o texto da experimentação artística que está sendo desenvolvida em espaços públicos e coletivos? Seria possível trazer a experiência carne/asfalto para o ato da escrita?

Para tentarmos responder a essa questão voltaremos ao poeta francês Charles Baudelaire. Baudelaire, considerado como o percussor da poesia moderna, expressou em seus poemas os sentimentos dos habitantes de uma cidade em processo de construção e modernização: a Paris remodelada por Barão de Haussmann.

Enquanto trabalhava em Paris, a tarefa de modernização da cidade seguia seu curso, lado a lado com ele, sobre sua cabeça e sob seus pés. Ele pôde ver-se não só como espectador, mas como participante e protagonista desta tarefa em curso; seus escritos parisienses expressam o drama e o trauma aí implicados (BERMAN, 1987, p. 143).

Como aponta Berman, Baudelaire não apenas observou - tal qual espectador - à distância às transformações da antiga Paris em uma cidade moderna. Baudelaire experimentou tal transformação na pele. Assumindo a figura do flâneur o poeta caminhava, aventurava-se sem rumo, perdia-se pelas ruas da cidade, misturava-se à multidão... A atividade cotidiana de Baudelaire pela cidade de Paris, a flanância, se constituiu como método e tema de sua obra e de seu pensamento crítico. Para ele o artista moderno não poderia se isolar e se proteger do mundo, pelo contrário, Baudelaire criticava efusivamente os artista de sua época que " vive muito pouco, ou nada, no mundo moral e político. Aquele que habita no bairro de Bredá ignora o que se passa o faubourg Saint-Germain" (BAUDELAIRE, 2006, p. 245).

Nessa relação corpo-a-corpo com a cidade, Baudelaire dividia-se entre excitação da nova vida moderna urbana e a nostalgia da destruição da antiga cidade. Revelando em suas criações o choque que o cidadão moderno passava naquele momento de profunda transformação da sociedade e do seu ambiente de convívio. Como a própria modernidade, oflâneur de Baudelaire era ambivalente e complexo. Assim, o choque da modernidade aflora nos escritos de Baudelaire com toda potência, exatamente porque ele os experimentava na carne. "Ao mesmo tempo que era crescente o fascínio pelo tema da multidão (...) uma certa melancolia crítica pelo desaparecimento da cidade antiga, retratada por fotógrafos, (...) estava também presente em Baudelaire, formando assim uma ambiguidade permanente" (JACQUES, 2012, p. 57).

Dessa maneira a flanância, que era possível apenas pela existência da cidade moderna, era ela mesma um contraponto à cidade. O flâneur, não podendo ser a solução de tal conflito, era a própria tensão dos dois opostos: o deambular pelas ruas, 
inebriado pelas experiências urbanas e de multidão, e a possibilidade de assimilação da experiência apenas pelo fato de diferenciar-se dela. Em um ensaio de Sobre a fotografia Sontag define em apenas uma expressão duas das mais importantes características do movimento corporal do flâneur: errante voyeurístico (SONTAG, 2004). Errante, pois caminha sem rumo ou objetivo entregue ao acaso, à curiosidade e ao seu desejo - o poeta flâneur se opõe à prerrogativa do caminhar objetivo da cidade moderna. Voyeurístico, pois o poeta não se entrega à cidade a ponto de perder-se. Antes, mantém uma distância controlável e estratégica, como alguém que - na tensão entre entregar-se ou não - ainda poderá escrever e criar poesia sobre a sua experiência.

No poema A uma passante, o poeta expressa o encontro que tem com uma desconhecida no meio de uma multidão. A visão - fugaz - traz em sua mente todos os tipos de potencialidades que aquele acontecimento abarca. No entanto, é apenas no entrever dessas potencialidades, apenas enquanto possibilidades, sem concretização, é que reside a sua poesia. Baudelaire mantém distância e não se entrega à tentação de conhecer aquela mulher. Se mantém fiel à ideia do errante voyeurístico que está atento às possibilidades da multidão, sem esgotá-las. Assim, podemos entender seu poema-instantâneo colado à sua proposta prática de flanância. A flanância pelas ruas da cidade é a própria fonte de sua poesia. É apenas nessa prática cotidiana que ele poderá ter um encontro fortuito com uma desconhecida que passa, e ter todas as sensações corpóreas que esse encontro pode suscitar - e é desse instante concentrado de energia, que converge em único segundo, como em um instantâneo de fotografia, que ele irá criar o seu poema. A poética de Baudelaire, portanto, está intimamente ligada à sua sensação física. À relação de seu corpo com o mundo a seu entorno. A poesia de Baudelaire seria o gérmen da poesia moderna que, agora, nos apresenta um novo desafio: tendo abolido os modelos e regras da tradição, novas formas e critério de análises também se farão necessárias.

O teórico francês Dominique Rabaté recentemente abordou o tema em seu livro Gestes Lyriques, no qual defende que a partir da poesia moderna não podemos mais encontrar os antigos padrões e formatos na produção poética, mas podemos entrever gestos dos autores.

Produzido por um sujeito, o gesto está ligado a um impulso que pode vir tanto de dentro, quanto de fora. Mais ou menos voluntário, mais ou menos eloquente, o gesto se trabalha, à maneira dos pintores ou dos mestres de artes marciais que insistem, tanto uns quanto outros, no estranho desapego de si, o qual se deve alcançar para o executar da maneira mais perfeita (RABATÉ, 2013, p. 14, tradução da autora). 
Rabaté considera, de fato, Baudelaire como o grande precursor deste novo lirismo. Segundo o crítico, em seus poemas, Charles Baudelaire "abre janelas". Janelas são maneiras de acessar algo, mas mantendo, ainda, uma distância segura. O gesto de criar e abrir certas janelas, portanto, está intrinsicamente ligado à atividade da flanância, e ao seu caráter voyeurístico.

A análise de Rabaté reforça, portanto, o que já havíamos apontado no início do artigo, a mudança de método - neste caso da poesia - indica uma outra transformação, de maior alcance. A cidade moderna transformou o homem-escritor, ele agora circula livremente, curioso e afetado por uma cidade efervescente, pulsante e ruidosa. Esse escritor já não pode mais seguir antigos formatos. Na medida em que o corpo moderno e a sua experiência vão tomando conta da produção artística, regras anteriores acabam sendo abandonadas. A poesia de Baudelaire, portanto, não segue modelos pré-estabelecidos - estrofes, rimas, sílabas ela tem forma livre, assim como o próprio flâneur. Não segue as linhas definidas e planejadas das ruas e avenidas, antes deambulam e se movimentam sem rumo, guiados pelo desejo.

A abolição das estruturas pré-determinadas e a invenção de novas formas não ficou, no entanto, restrita à poesia moderna. No mesmo período, como se sabe, diversos dramaturgos iniciaram uma implosão dos modelos dramáticos vigentes que, aos poucos, iam sendo derrubados e transformados. Autores como Ibsen, Tchekhov ou Strindberg deram o ponta pé inicial na demolição das estruturas do drama que acabariam por ser completamente destruídas em experimentações mais radicais no século XX. A eliminação dos modelos dramáticos pré-existentes, por fim, além de colocar críticos teatrais diante de um desafio - quando se abolem as regras e os formatos que definem um gênero vemos surgir uma produção heterogênea e polifônica, difícil de ser definida e analisada - também não poupou os dramaturgos que, diante de uma produção livre de modelos, precisam experimentar novos métodos.

Assim, na ocasião da criação, em processo colaborativo, de Antídoto para impossibilidades e paralisias - um espetáculo/intervenção na rua e para a rua - me vi diante de tais questões e encontrei no conceito de gesto uma nova maneira de provocar os atores para deles obter contribuições dramatúrgicas. Apoiada nesse conceito busquei detonadores de experiências corporais a fim de instigar os atores na produção de textos poéticos. A principal preocupação era encontrar maneiras de estimular criações que não passassem necessariamente pelo drama ou pela já conhecida forma performática de "confissão"3. Inspirei-me, assim, em Baudelaire e em outras experiências de escritas urbanas - como a de André Breton em Nadja ou Helio Oiticia e seu Delirium Ambulatorium - para
3. Consideramos aqui a confissão como procedimento dramatúrgico já amplamente difundido no teatro performativo contemporâneo e que foi muito precisamente analisado por Oscar Cornago em seu artigo "Atuar de 'verdade'. A confissão como estratégia cênica". 
convocar os próprios corpos dos atores na criação dessa textualidade gestual.

Para que se compreenda melhor os caminhos tomados pela dramaturgia descreveremos aqui, brevemente, os pontos de partida para a criação do espetáculo. O processo foi iniciado antes de minha chegada - quando a diretora se uniu à jovens atores em formação para criar uma peça entorno da depressão juvenil. O aumento de casos de distúrbios psíquicos nessa nova geração, o grande número de jovens utilizando medicamentos psiquiátricos e a imobilidade diante da realidade foram os temas que impulsionaram o trabalho. A direção elegeu As três irmãs de Anton Tchekhov como texto-inspiração para o processo. A peça russa não foi escolhida por acaso, o texto trata exatamente da imobilidade, da paralisia, da não-ação dos personagens que, ao invés de criarem uma outra realidade, sonham melancólicos com um retorno impossível à idealizada Moscou. Em um primeiro momento a ideia era criar um espetáculo em sala convencional, porém, não muito tempo depois do início dos ensaios, a diretora optou por sair das salas fechadas e passou a idealizar/criar uma peça nas ruas da cidade. Tal mudança de ambiente acabou por abrir uma outra camada no trabalho, já que agora parecia inevitável relacionar o estado psíquico desses jovens e o modo de vida na cidade de São Paulo. Fui chamada nessa segunda etapa, quando se procurava a criação de uma dramaturgia itinerante que se passaria nas ruas do bairro da Liberdade e que pretendia evidenciar os efeitos que a urbanização violenta, desregulada e desigual causa nos indivíduos que habitam São Paulo, assim como refletir sobre os motivos por trás desse tipo de urbanização. Também pretendíamos que o espetáculo fosse uma intervenção no fluxo habitual da cidade, mesmo para aqueles transeuntes que não fossem nossos espectadores, abrindo espaços poéticos para outras formas de experimentação e vivência da cidade.

Mantivemos a inspiração na peça de Tchekhov, contudo, a fábula de As três irmãs não fazia mais sentido, dado que sua ficção trata de ambientes e relações privadas, restritas às quatro paredes - o oposto do caminho que pretendíamos tomar. Decidimos, então, abraçar o argumento que já havia aparecido anteriormente no processo - um congresso médico onde se estuda um surto epidêmico de uma síndrome, já diagnosticada anteriormente pelo "Dr. Tchekhov" em As três irmãs - localizamos, no entanto, esse argumento, em um futuro distópico, onde os médicos realizam experimentos em cobaias humanas e o público é convidado a testemunhar a experiência - como se fosse cientistas integrantes da equipe. Baseados nessa sinopse pudemos desenvolver algumas ferramentas importantes para o próximo passo da dramaturgia: 1) nesse momento futuro um 
surto da chamada "Síndrome de Moscou" estava apresentando diversas formas - Síndrome de Andrei, Síndrome de Macha, Síndrome de Irina e Síndrome de Olga - cada uma delas apresentam sintomas diversos e levam a diferentes consequências, todas, porém, preocupam o governo totalitário da cidade em questão; 2) por se tratar de uma ficção científica pudemos assumir aparelhos de MP3 como se eles fossem dispositivos de leitura de pensamento das cobaias - facilitando a instauração de uma atmosfera sonora que envolveria cada um dos espectadores nas palavras poéticas dos monólogos internos de cada uma das figuras.

Tendo tomado tais decisões seria necessário definir as características de cada uma das síndromes e encontrar gestos que as representassem, a fim de provocar os atores na criação textual que cada espectador ouviria em seu aparelho de MP3. Mais uma vez é importante salientar que a ideia não era criar situações dramáticas - diálogos intersubjetivos baseados em ações - assumindo personagens ficcionais, como também não se tratava de coletar depoimentos reais dos performers. Antes, nos interessava captar textos que abrissem os olhos do público para outras relações com a cidade e para outras leituras poéticas da paisagem urbana. Estaríamos, portanto, em um local intermediário, não no território da personagem e, tampouco, no depoimento/confissão pessoal do performer. Seriam textos-intervenções poéticas que seguiriam as características escolhidas para a síndrome específica que a cobaia apresentava - no campo da ficção -, mas as palavras seriam criadas pelos performers a partir de experiências reais nas ruas de São Paulo. O intuito seria o de criar gestos líricos que se dirigissem ao espectador e que possibilitassem a instauração de uma nova perspectiva estética, poética e política sobre a cidade. A seguir elencaremos a definição de cada síndrome, algumas das provocações/experiências propostas para os atores, assim como alguns trechos dos textos criados e uma breve análise sobre o resultado alcançado.

A partir de uma análise das características dos personagens centrais de As três irmãs - Olga, Macha, Irina e Andrei - criamos as síndromes que seriam pesquisadas pelos médicos em Antídoto para impossibilidades e paralisias. Olga, irmã mais velha, inspirou-nos na criação de uma síndrome de apego ao passado, apego tão profundo e cego que não permitira o doente a viver o presente. A síndrome de Macha seria aquela de depressão tão profunda que a impossibilitaria de enxergar uma possibilidade de futuro, ela estaria imersa nos sofrimentos corporais do aqui/agora, descrevendo e sentindo cada segundo como se não existisse possibilidade de sonhar um amanhã. Irina inspirou-nos a criar uma síndrome de quem idealiza a 
criação de um novo lugar, no futuro, que solucionaria todos os problemas do presente. A idealização porém é romântica, inocente e nunca a levada à prática. Já a síndrome inspirada no irmão Andrei seria a do vício, que levaria à falta de memória e à confusão mental. Cada uma dessas síndromes, no plano da ficção, precisariam ser controladas, dado que levavam os indivíduos portadores à não produção e à falta de desejo de consumo. $\mathrm{O}$ alastramento delas significaria, portanto, uma crise no sistema econômico. A equipe médica fora, assim, contratada pelo governo deste local ficcional para investigar os portadores da síndrome e como eles reagem quando inseridos na sociedade. O público era, então, levado a seguir as cobaias humanas na cidade, observando como elas interagiam com a vida urbana e ouvindo - através do "dispositivo de leitura de pensamentos" - o que se passava em suas mentes. Foi, portanto, na criação de tal tessitura poética de cada uma das cobaias que a dramaturgia se debruçou, em colaboração com os atores ${ }^{4}$.

\section{Sindrome de Macha}

Para a criação poética do universo mental e emocional da portadora da Síndrome de Macha algumas provocações e experiências foram propostas, sempre tendo em vista o fato dessa cobaia não conseguir vislumbrar o futuro, viver imersa nas sensações do presente e acabar por se diluir na cidade. A portadora da síndrome enxerga e observa cada detalhe e mazela da vida urbana como se fosse as suas próprias. Projetando-se na cidade e, assim, também, humanizando São Paulo.

Duas das experiências, que narraremos aqui, formaram o primeiro trecho textual do espetáculo quando esse ganhava as ruas. Nele os gestos pretendidos pela dramaturgia era o de apontar e ampliar - como em uma lente de aumento - as pequenas cicatrizes e poesias da cidade. Para a criação desse texto pedimos que a atriz fizesse o mesmo percurso que o público faria mais tarde, diversas vezes. Em algumas delas apenas olhando e reparando o chão. Em outras apenas olhando e observando o céu. A partir dessas simples trajetórias a atriz deveria escrever dois textos. Posteriormente os textos foram editados e fundidos pela dramaturga.

"Eu andei por cima de muitos buracos. Rachaduras. Craquelados. Marcas e marcas. Cinza escuro, cinza claro, vermelho tijolo, preto, cor de burro quando foge com poças de água suja. Não vi o rosto de ninguém que atravessou o caminho, mas agora conheço esse trajeto muito bem. Deve ser muito ruim viver de cabeça baixa. Os ombros pesam, o pescoço involuntariamente dá força pra cima, pra frente."/"Lixo. Duas baratas estateladas, quase desfeitas. Pedras desniveladas.
4 Os atores-criadores que colaboraram na criação e que terão trechos de seus textos citados são: Carolina Froes (Macha) e Rafael Sampaio (Andrei). Também julga-se importante informar o leitor que o espetáculo começava em horário comercial em dia de semana - 16:30h e terminava e plena hora do rush $-19 h$. 
Desenhos desiguais e padrões misturados. O retrato de uma cidade toda no chão.") "E o céu que até então era uma ruazinha estreita, se abriu na repetição de um grande vão."/ "As nuvens se misturam tão bonitas que eu gostaria mesmo era de subir até lá e me derreter no misturar." Tais trechos ajudavam a criar um universo em que a observação da cidade levava à própria observação - a confusão entre esses dois corpos - o urbano e o humano que o atravessa - são da atriz/cobaia, mas também podem ser do próprio público que é levado a reparar no chão em que pisa, no céu acima dele e na sua própria postura diante da cidade. Dessa maneira, como explicaria Rabaté "o gesto efetuado pelo texto poético não é apenas aquele que o escritor, se ele conseguir, descreve. Ele se torna também o gesto do leitor e do ouvinte. (...) É mais ou menos como o ajuste de uma experiência singular à uma outra experiência singular" (RABATÉ, 2013, p. 12, tradução da autora).

\section{Sindrome de Andrei}

O universo poético da cobaia portadora da Síndrome de Andrei deveria ser de confusão e amnesia, como o de alguém que acorda em uma metrópole imensa, sem se lembrar como chegou ali e o que pode fazer para partir. Entre o embriagado, o esquecido e o perdido, essa figura nos lembraria o quanto deixamos de lado algumas sensações corpóreas neste modo de vida e como muitas vezes nos sentimos engolidos e perdidos nesta realidade urbana. Buscamos, assim, que seus textos-intervenções poéticas tivessem como gesto propulsor de confundir.

Em duas das experiências propostas ao ator, tentamos concretizar tais sensações: em uma primeira pedimos para que ele se embriagasse e reparasse em todas as sensações de seu corpo; em uma outra foi proposto que o ator entrasse em um ônibus com destino desconhecido, sem seu celular, descesse no ponto final e tentasse voltar para casa de transporte público. Ambas as experiências deveriam ser seguidas do ato da escrita. A mistura dos textos gerados instaurou a sensação de confusão mental e embriaguez que buscávamos e, quando ouvido pelos fones do MP3 em plena cidade, incluía o público nessa sensação, que acabava a relacionando diretamente com o caos urbano."Eeeeeeepa! Está giraaaando maluco! O mundo gira... Já parou pra sentir!?Oh...O ventinho. Epa que esse mundo está girando rápido e me deixando tonto!Paro! Paro! Respira...Fundo. Um cigarro...Tragar... Fundo. Isso mata! Aham... Mata mesmo! Mas já estamos morrendo."/ "Tá. Ainda estou em segurança. Ainda sei o caminho de volta"/ "O mundo gira mesmo!"/ "Um Marlboro blue ice e você não tem água né? Tudo bem... Estou perdido." 
Os textos, como se pode ver, tem o linguajar do ator, palavras específicas que apenas ele usaria naquela situação em que estava. Portanto, a poética gerada é própria daquele criador, ainda que ele tenha sido provado por um olhar dramatúrgico prévio, a textura poética de cada ator-criador é preservada. São textos que não deixam de ser performativos, apesar de não serem confissões ou depoimentos pessoais, pois remetem a uma experiência concreta daquele corpo e são expressões de suas sensações físicas e emocionais mais materiais. Uma fábula até pode ter sido criada para abarcar os gestos líricos citados, porém a experiência mais importante para o público era a de estar imerso nessas palavras não dramáticas - dado que não estavam ligadas à psicologia e a ações de personagens ficcionais - que abriam o corpo do próprio espectador em diversas sensações corporais de estar aqui/agora na cidade de São Paulo. Tal experiência era ainda mais radicalizada pela forma como o texto chegava ao público - pelos fones de ouvido do MP3, o que criava um universo intimista e imersivo.

Nesse breve relato que nos foi possível fazer - dado o curto espaço - tentamos debater maneiras de como a dramaturgia contemporânea, na ocasião de uma criação na e para a rua pode incluir a relação corpo/cidade em sua elaboração. O caminho do gesto nos parece um caminho rico para compreender outras possibilidades de textos que convocam a criação performativa do e que pode gerar textos teatrais a partir das relações específicas entre o ator e o ambiente no qual ele está inserido, dependendo do recorte provocativo do dramaturgo. Nesse sentido, entendemos que a função do dramaturgo se torna o de provocar experiências para catalisar a criação de textos, o que faria surgir uma dramaturgia intimamente ligada àqueles criadores e àquele espaço no qual se cria. 


\section{REFERÊNCIAS}

BAUDELAIRE, C. A invenção da modernidade. Lisboa: Relógio d'água, 2006.

BERMAN, M. Tudo que é sólido desmancha no ar - a aventura da modernidade. São Paulo: Cia das Letras, 1987. (Tradução: Pedro Tamem).

CORNAGO, O. Atuar de 'verdade'. A confissão como estratégia cênica. Revista Urdimento, Florianópolis, n. 13, pp. 99-111, set 2009.

JACQUES, P.B. Elogio aos errantes. Salvador, EDUFBA, 2012.

PELBERT, P. P. A vida desnudada. In: Leitura da morte. São Paulo: Annablume, 2007.

RABATÉ, D. Gestes Lyriques. Mayenne: Éditions Corti, 2013.

SONTAG, S. Sobre fotografia. São Paulo: Companhia das Letras, 2004. WILLIAMS, R. Drama em cena. São Paulo: Cosac Naify, 2010. 